\title{
Synthesis of High Capacity Cathodes for Lithium-Ion Batteries by Morphology-Tailored Hydroxide Co-precipitation
}

Dapeng Wang ${ }^{1,2}$, Ilias Belharouak ${ }^{1 \|_{*}}$, Luis. H. Ortega ${ }^{1}$, Xiaofeng Zhang ${ }^{1}$, Rui Xu ${ }^{1}$, Dehua Zhou ${ }^{1}$, Guangwen Zhou ${ }^{2}$ and Khalil Amine ${ }^{1 *}$

${ }^{1}$ Chemical Sciences and Engineering Division, Argonne National Laboratory, 9700 South Cass Ave. Argonne, IL 60439

\# Qatar Environment and Energy Research Institute, Qatar Foundation, P.O. Box 5825 Doha, Qatar

${ }^{2}$ State University of New York at Binghamton, Binghamton, NY, 13902

*To whom correspondence should be addressed

Email: amine@gmail.com, belharouak@anl.gov 


\begin{abstract}
Nickel manganese hydroxide co-precipitation inside a continuous stirred tank reactor was studied with sodium hydroxide and ammonium hydroxide as the precipitation agents. The ammonium hydroxide concentration had an effect on the primary and secondary particle evolution. The two-step precipitation mechanism proposed earlier was experimentally confirmed. In cell tests, Li- and Mn-rich composite cathode materials based on the hydroxide precursors demonstrated good electrochemical performance in terms of cycle life over a wide range of lithium content.
\end{abstract}

Keywords: Lithium batteries, Hydroxide Co-precipitation, Ammonia, Cathode, Continuously stirred tank reactor CSTR. 


\section{Introduction}

As one of the most promising cathode materials with high energy density, Li- and Mn-rich composites have been investigated for over 10 years. ${ }^{[1,2]}$ However, this material suffers from the drawback that a tradeoff is needed between rate performance and volumetric energy density.

The routine procedure for the synthesis of the composite cathode material involves two steps ${ }^{[3-12]}$ : precursors are synthesized through co-precipitation reactions, then the precursors are lithiated through high-temperature solid state reactions. Previous studies suggested that the properties of the $\mathrm{Li}$ - and $\mathrm{Mn}$-rich cathode materials are greatly affected by the precursor, specifically, the composition, ${ }^{[2,6,13-16]}$ particle morphology, ${ }^{[10,17,18]}$ and size distributions. ${ }^{[19]}$ Tailoring the precursor morphology is one effective way to tune the material to be a high power or high energy cathode.

Carbonate and hydroxide co-precipitations are the most popular methods to prepare the cathode precursors. Carbonate co-precipitations have the merits of facile morphology control and environmental friendliness. ${ }^{[10]}$ However, before the steady state of the continuous reaction is reached, the particle usually becomes so large that the synthesized cathode cannot deliver decent rate capacity. ${ }^{[20]}$ What is more, void layers between the adjacent rings in the onion-like particle morphology render the cathode materials too fragile to achieve high electrode density.

Hydroxide co-precipitation does not have the limitations mentioned above; however, it is much more complex than the carbonate process, especially when a high manganese content composition is involved, for the following reasons. First, hydroxide precipitation can result in different structures. For example, both $\mathrm{Ni}(\mathrm{OH})_{2}$ and $\mathrm{Co}(\mathrm{OH})_{2}$ 
can be $\alpha$ phase, $\beta$ phase, or $\beta_{b c}$ phase, which highly depends on the synthesis conditions. ${ }^{[21-24]}$ The most reliable phase for the synthesis of $\mathrm{Li}$ - and Mn-rich cathode materials is $\beta$ phase because its structure is impurity and defect free. Second, $\mathrm{Mn}_{3} \mathrm{O}_{4}$ always coexists with manganese hydroxide during the various stages of cathode synthesis (e.g., co-precipitation, precursor washing, lithiation). This is because in $\mathrm{Mn}(\mathrm{OH})_{2}, \mathrm{Mn}^{2+}$ can easily oxidize to $\mathrm{Mn}^{3+}$ and then becomes segregated in the form of mixed hydroxides. $[10,25]$ Third, hydroxide primary particles tend to adopt lamellar or needle-like morphology, which poses a challenge in preparing densely packed secondary particles. ${ }^{[26-}$ 28]

In this research, we studied the co-precipitation reaction with sodium and ammonium hydroxide for the formation of $\mathrm{Li}$ - and $\mathrm{Mn}$-rich cathode materials, in particular, the effect of ammonia concentration on the growth of the primary and secondary particles. Although ammonia is widely used in precipitation reactions to (1) maintain a relatively stable $\mathrm{PH},(2)$ achieve homogeneous distribution for different metal ions by chelating effect, ${ }^{[10,27,29-31]}$ our study is the first systematic investigation to highlight its function as precursor morphology tailor by tuning (1) primary particle morphology (2) the packing behavior of the primary particles to form loosely or densely packed secondary particle. Coin cell tests of cathodes fabricated by the hydroxide coprecipitation demonstrated reasonable electrochemical performance.

\section{Experiments}

Nickel sulfate hexahydrate $\left(\mathrm{NiSO}_{4} \cdot 6 \mathrm{H}_{2} \mathrm{O}\right)$, manganese sulfate monohydrate $\left(\mathrm{MnSO}_{4} \cdot \mathrm{H}_{2} \mathrm{O}\right)$, sodium hydroxide $(\mathrm{NaOH})$, and ammonium hydroxide $\left(\mathrm{NH}_{3} \cdot \mathrm{H}_{2} \mathrm{O}\right)$ were used as the starting materials to synthesize $\mathrm{Ni}_{0.25} \mathrm{Mn}_{0.75}(\mathrm{OH})_{2}$ precursor in a continuously 
stirred tank reactor (CSTR). The feed rate of the transition metal solution was fixed at $16 \mathrm{ml} / \mathrm{min}$, while the pumping rate of the base solution (mixture of $\mathrm{NaOH}$ and $\mathrm{NH}_{3} \cdot \mathrm{H}_{2} \mathrm{O}$ ) was controlled by a $\mathrm{pH}$ controller. The precipitation reaction was conducted at a constant temperature $\left(60^{\circ} \mathrm{C}\right)$ and a fixed stirring speed $(1000 \mathrm{rpm})$. An $\mathrm{N}_{2}$ cover gas was introduced into the CSTR to prevent $\mathrm{Mn}^{2+}$ oxidation. The precursor materials were collected for two hours after 8 hours precipitation reaction. Longer reaction time may lead to better particle morphology and tap density, but determining the optimized reaction conditions is beyond the scope of this study.

The collected samples were washed with de-ionized water several times to remove residual sodium and sulfur species, then filtered and dried inside a vacuum oven set at $100^{\circ} \mathrm{C}$ for 24 hours. Finally, Li- and Mn-rich cathode materials, $\mathrm{Li}_{\mathrm{x}} \mathrm{Ni}_{0.25} \mathrm{Mn}_{0.75} \mathrm{O}_{2.5+\delta}(1.54 \leq \mathrm{x} \leq 1.71)$, were prepared through a solid state reaction between appropriate amounts of $\mathrm{Ni}_{0.25} \mathrm{Mn}_{0.75}(\mathrm{OH})_{2}$ and $\mathrm{Li}_{2} \mathrm{CO}_{3}$ at $900^{\circ} \mathrm{C}$ for 14 hours.

The morphology and particle size distribution of the precursor and cathode materials were characterized with a cold field emission scanning electron microscope (SEM, Hitachi S-4700-II) and particle size analyzer (Cilas1090), respectively. Tap density of the precursor was measured with Autotap from Quantachrome. The crystal structures of the precursor and cathode materials were determined by powder X-ray diffraction (XRD) with a D5000 Siemens X-ray diffractometer, using a $\mathrm{Cu}-\mathrm{K} \alpha$ radiation source $(\lambda=1.5406 \AA)$. The samples were scanned from $2 \theta=5^{\circ}$ to $80^{\circ}$ at a rate of $0.1^{\circ} / 20 \mathrm{~s}$. The chemical compositions were determined with inductively coupled plasmamass spectroscopy (ICP-MS, Agilent Technologies 7700 series). 
Electrochemical characterizations were conducted in CR2032 coin-type cells. Cathodes were composed of synthesized Li- and Mn- rich cathode materials (80 wt $\%$ ), acetylene black (10 wt $\%)$, and polyvinylidene difluoride binder (10 wt $\%)$. A slurry of this mixture was coated onto an aluminum foil and dried at $85^{\circ} \mathrm{C}$. The lithium cells were assembled inside a helium-filled glove box with lithium metal as the counter anode, Celgard 2325 membrane as the separator, and $1.2 \mathrm{M} \mathrm{LiPF} 6$ dissolved in ethylene carbonate and ethyl methyl carbonate (3:7 volume ratio) as the electrolyte. The cells were tested with a 2.0-4.6 V voltage window and a $\mathrm{C} / 3$ discharge current. (In our calculations, the $1 \mathrm{C}$ rate is assumed to be equal to $200 \mathrm{~mA} / \mathrm{g}$.)

\section{Results and discussion}

Table 1 lists the experimental parameters used to synthesize $\mathrm{Ni}_{0.25} \mathrm{Mn}_{0.75}(\mathrm{OH})_{2}$ precursors. The only variation was the base solution composition. To explore the ammonia effect on the precipitation process, the molar ratio between sodium hydroxide and ammonium hydroxide $\left(\mathrm{M}_{\mathrm{S}} / \mathrm{M}_{\mathrm{A}}\right)$ was gradually increased from 2:3 (experiment \#1) to 4:1 (experiment \#6). The tap densities of the dried precursors were also measured and are

listed in Table 1. Most of the precursors have relatively low tap density $\left(<0.84 \mathrm{~g} / \mathrm{cm}^{3}\right)$, except for that from experiment \#2 $\left(1.5 \mathrm{~g} / \mathrm{cm}^{3}\right)$.

The tap density of the powder material is a reflection of the secondary particle size distribution and the primary particle packing within secondary particles. We found that ammonia concentration has a direct impact on both of the secondary particle growth rate and the primary particle packing. Evolutions of D50 particle size for four $M_{S} / M_{A}$ ratios are compared in Figure 1. Neither the low $\mathrm{M}_{\mathrm{S}} / \mathrm{M}_{\mathrm{A}}$ ratio (2:3, red line in Figure 1) nor the high $\mathrm{M}_{\mathrm{S}} / \mathrm{M}_{\mathrm{A}}$ ratio (4:1, black line in Figure 1) benefits the secondary particle 
growth. After 10 hrs reaction, the D50 values were still under $10 \mu \mathrm{m}$ for these two ratios. At $\mathrm{M}_{\mathrm{S}} / \mathrm{M}_{\mathrm{A}}=3: 2$ (olive line in Figure 1), D50 values increased with reaction time and stabilized between 10 and $11 \mu \mathrm{m}$ after $5 \mathrm{hr}$. Decrease of $\mathrm{M}_{\mathrm{S}} / \mathrm{M}_{\mathrm{A}}$ to $1: 1$ significantly boosted the initial growth rate (blue line in Figure 1): D50 quickly reached $23 \mu \mathrm{m}$ from the initial $8 \mu \mathrm{m}$ in the first $4 \mathrm{hr}$, with an average growth rate of $4.28 \mu \mathrm{m} / \mathrm{hr}$, after which, D50 rapidly shrunk to $9 \mu \mathrm{m}$ and became stabilized at this size. One hypothesis is that when the agglomerates approach a critical size, the shear stress exerted on the agglomerates by the hydrodynamic motion becomes larger than the cohesive force among primary particles, and then the agglomerates break down to smaller fragments, resulting in smaller D50. Different stirring rates and agglomerate population densities within the reactor could affect the agglomeration growth rate significantly, which is beyond the purpose of this study and will be discussed in separate papers.

The above hypothesis is supported by Figure 2, which shows the particle size distributions of hydroxide precursors collected for six $\mathrm{M}_{S} / \mathrm{M}_{\mathrm{A}}$ ratios. Most of the histogram curves have maxima at $0.3 \mu \mathrm{m}, 2 \mu \mathrm{m}$, and $10 \mu \mathrm{m}$, which correspond to -crystal nuclei, agglomerate fragments, and agglomerates, respectively. The peak intensity at 10 $\mu \mathrm{m}$ is much higher than those at $0.3 \mu \mathrm{m}$ and $2 \mu \mathrm{m}$ (see inset to Figure 2), indicating the precipitate is mainly in the form of agglomerates. The relatively sharp peaks at $10 \mu \mathrm{m}$ also show that the agglomerates are narrowly distributed. A process involving two levels of particle agglomeration $(1-2 \mu \mathrm{m}$ and $10 \mu \mathrm{m})$ was proposed in our previous report. ${ }^{[32]}$ We concluded that even though the growth rates varied for experiments with different $\mathrm{M}_{\mathrm{S}} / \mathrm{M}_{\mathrm{A}}$ ratios, the particle growth follows the same two-level agglomeration mechanism. 
The effect of $\mathrm{M}_{\mathrm{S}} / \mathrm{M}_{\mathrm{A}}$ ratio on the agglomerate morphology is shown by the SEM images in Figure 3. Both low (2:3) and high (4:1) $\mathrm{M}_{\mathrm{S}} / \mathrm{M}_{\mathrm{A}}$ ratios led to loosely packed secondary particles with irregular morphology (Figures $3 \mathrm{a}$ and $3 \mathrm{f}$, respectively). For $\mathrm{M}_{\mathrm{S}} / \mathrm{M}_{\mathrm{A}}$ of $1: 1$, the agglomerates are spherical with a very narrow particle size distribution (Figure 3b), which can be attributed to the higher tap density of the precursor (see Table $1)$.

The various agglomerate morphologies are a result of the diverse packing behaviors of the primary particles synthesized with different $\mathrm{M}_{\mathrm{S}} / \mathrm{M}_{\mathrm{A}}$ ratios. The SEM images in Figure 4 show the effect of ammonia content on the primary particle morphology. In general, all of the precursors are lamellar with a lateral dimension around $500 \mathrm{~nm}$. When the ammonia concentration is low (Figures $4 \mathrm{a}$ and $4 \mathrm{~b}$ ), the primary particles are multi-layered plates with rough edges. With increase of $M_{S} / M_{A}$ ratio from $2: 3$ to $1: 1$, the thickness of the nanoplates increased from $\sim 50 \mathrm{~nm}$ to $>100 \mathrm{~nm}$, which increased the mass of the agglomerates, and thereby enhanced the chance of effective collisions of agglomerates with the other agglomerates and reactor wall/agitator that can cause the agglomerate shape to be spherical. Further increase in $\mathrm{M}_{\mathrm{S}} / \mathrm{M}_{\mathrm{A}}$ ratio up to 5:2 led to single-layer plates with smooth basal surfaces (Figures $4 \mathrm{c}$ to $4 \mathrm{e}$ ). Their irregular edges are the result of particle disruption created by strong fluid shear forces in the CSTR. At the $M_{S} / M_{A}$ ratio of 4 , the primary particles became regular hexagonal plates (Figure $4 f$ ), which may relate to the anisotropic growth of the six-fold symmetric crystallites.

Two reaction paths were earlier proposed for the metal hydroxide precipitation in the presence of ammonia. One group of researchers stated that the metal ions in the solution first coordinate with ammonia to form a complex, and then slowly release into 
the solution, where they react with hydroxyl group to form hydroxide precipitates. ${ }^{[29,33]}$ The step-wise reactions can be expressed as:

$$
\begin{aligned}
& \text { T.M. }{ }^{2+}+n \mathrm{NH}_{4} \mathrm{OH}(a q) \rightarrow\left[\text { T.M. }\left(\mathrm{NH}_{3}\right)_{n}\right]^{2+}(a q)+n \mathrm{H}_{2} \mathrm{O} \\
& {\left[\text { T.M. }\left(\mathrm{NH}_{3}\right)_{n}\right]^{2+}(a q)+2 \mathrm{OH}^{-} \rightarrow \text { T.M. }(\mathrm{OH})_{2}(s)+n \mathrm{NH}_{3}}
\end{aligned}
$$

where T.M. is the abbreviation of transition metal (Ni, Mn in our case). Other researchers proposed that the hydroxide precipitation involves a dissolution-recrystallization process: ${ }^{[34]}$

$$
\text { T.M. }(\mathrm{OH})_{2}(s)+n N H_{3} \leftrightarrow\left[T \cdot M \cdot\left(\mathrm{NH}_{3}\right)_{n}\right]^{2+}(a q)+2 O H^{-}
$$

The precipitate is thus a result of dynamic equilibrium between the solid metal hydroxide and aqueous metal ammonia complex.

In order to verify these proposed growth mechanisms, we prepared base solutions with $\mathrm{M}_{\mathrm{S}} / \mathrm{M}_{\mathrm{A}}$ ratio $=2: 3,1: 1$, and $4: 1$ (same as that in experiment \#1, \#2, and \#6, respectively). We separately added $1 \mathrm{~g}$ of the dried precursor collected from experiments $\# 1$, \#2, and \#6 to the corresponding base solution and kept the solutions at $60{ }^{\circ} \mathrm{C}$ for over two hours under magnetic stirring. Subsequently, the three precursor-basic solution mixtures were vacuum filtrated, and the filtrated supernatants were collected and labeled as (1), (2), and (3) respectively. At the same time, $\mathrm{NiSO}_{4}$ solution (green) and $\left[\mathrm{Ni}\left(\mathrm{NH}_{3}\right)_{n}\right]^{2+}$ solution (blue) were prepared as the color identities of $\mathrm{Ni}^{2+}$ and $\left[\mathrm{Ni}\left(\mathrm{NH}_{3}\right)_{n}\right]^{2+}$ (Figure 5). After 2 hours of aging, the color did not change for the three solutions, which indicates no obvious nickel dissolution in either the $\mathrm{Ni}^{2+}$ or $\left[\mathrm{Ni}\left(\mathrm{NH}_{3}\right)_{n}\right]^{2+}$ forms. In other words, the hydroxide precursor is more stable than the ammonia complex under the precursor synthesis conditions. Reactions (1) and (2) are thus believed to be the main reaction path for the co-precipitation. 
The crystal structure of the $\mathrm{Ni}_{0.25} \mathrm{Mn}_{0.75}(\mathrm{OH})_{2}$ precursors for the six base solutions was verified with powder XRD. As shown in Figure 6a, there are no obvious differences in the XRD patterns among the batches of precursors. The main structure of the precursors can be indexed based on the $P \overline{3} m$ space group. The minor peaks highlighted with arrows in Figure 6 correspond to a $\mathrm{Mn}_{3} \mathrm{O}_{4}$ phase (space group $I_{1} /$ amd), which is the result of $\mathrm{Mn}^{2+}$ oxidation. Select area electron diffraction confirmed the precursor was $\mathrm{TM}(\mathrm{OH})_{2}$ rather than TMOOH, which was discussed in detail in our previous study ${ }^{[32]}$. The composite structure of the precursors indicates that even though $\mathrm{N}_{2}$ cover gas was applied during the synthesis process, a certain amount of $\mathrm{Mn}^{2+}$ oxidized to $\mathrm{Mn}^{3+}$ during synthesis, washing, or drying. The dominant peak located at $2 \theta=19^{\circ}$ has a much higher intensity than the other peaks due to the anisotropic growth of the primary particles. The broad peaks between $35^{\circ}$ and $40^{\circ}$, according to previous reports, relate to stacking faults along the c-axis for the metal hydroxide, which is iso-structural to $\beta-\mathrm{Ni}(\mathrm{OH})_{2}$-like phase. ${ }^{[24]}$ Figure $6 \mathrm{~b}$ is the structural configuration of the $\beta-\mathrm{Ni}(\mathrm{OH})_{2}$-like phase, where Ni is replaced by " $\mathrm{M}$ " $(\mathrm{Ni}$ and $\mathrm{Mn})$, in which the $\mathrm{MO}_{6}$ octahedral layers stack along the $c$ axis, while the hydrogen atoms are located between nearby $\mathrm{MO}_{6}$ octahedral layers.

Cathode materials with various lithium contents were synthesized from precursor \#3 with solid state reactions, as described in the experimental section. The nickel-tomanganese atomic ratio is 1:3 based on ICP-MS analysis, exactly matched the nominal ratio. Figure 7 shows SEM images of primary particles with various lithium content. The measured lithium-to-transition metal atomic ratio is indicated in the upper right corner of each image. After lithiation, the primary particles maintain a lamellar morphology, but the edges are much thicker than those of the hydroxide precursors. It was found that, with 
the increase of lithium content, the average edge thickness linearly increased from 100 $\mathrm{nm}$ for the $\mathrm{Li}_{1.54} \mathrm{Ni}_{0.25} \mathrm{Mn}_{0.75} \mathrm{O}_{2+\delta}$ sample to $500 \mathrm{~nm}$ for the $\mathrm{Li}_{1.71} \mathrm{Ni}_{0.25} \mathrm{Mn}_{0.75} \mathrm{O}_{2+\delta}$ sample.

The structure of the cathode materials with varying lithium content was characterized with XRD, as shown in Figure 8(a). The diffraction patterns are similar for different lithium content, with a major phase corresponding to $\mathrm{LiNi}_{0.5} \mathrm{Mn}_{0.5} \mathrm{O}_{2}(R \overline{3} \mathrm{~m}$ space group) and a minor phase corresponding to $\mathrm{Li}_{2} \mathrm{MnO}_{3}$-like phase $(C 2 / \mathrm{m}$ space group). The right shifting of the (003) peak at $2 \theta=19^{\circ}$ when lithium content is increased is shown in Figure 8(b) (the 1.67Li sample is an outlier). This slow shift indicates a continuous shrinking of the c-axis lattice parameter. As the direction perpendicular to the c-axis is indicative of lithium ion fast diffusion, the decrease in the inter-planar distance along the c-axis should lead to reduced channel size and, therefore, possible decreased electrochemical performance, as discussed below.

The voltage profiles in the first cycle and capacity retention over 50 cycles are shown for six lithium cells in Figures 9 and 10, respectively. In Figure 9, all the voltage profiles exhibited the typical features of lithium- and manganese-rich composite material: in the charge process, a plateau appears around $4.5 \mathrm{~V}$, which is related to the activation of $\mathrm{Li}_{2} \mathrm{MnO}_{3}$-like phase; in the discharge process, a sloped curve rather than a plateau appears due to the concurrence of the reduction of $\mathrm{Ni}^{4+}$ and $\mathrm{Mn}^{4+}$ to $\mathrm{Ni}^{2+}$ and $\mathrm{Mn}^{3+}$, respectively. Compared to lithium-rich composite cathodes made from carbonate precursors $\left(\mathrm{C}_{\text {carbonate }}\right)$ in our previous study, ${ }^{[4]}$ cathodes based on hydroxide precursors $\left(\mathrm{C}_{\text {hydroxide }}\right)$ have slightly higher initial discharge capacities, and much better tolerance to lithium content variations. For example, an increase of 1.5 to $1.65 \mathrm{Li}$ in $\mathrm{Li}_{\mathrm{x}} \mathrm{Ni}_{0.25} \mathrm{Mn}_{0.75} \mathrm{O}_{2+\delta}$ for $\mathrm{C}_{\text {carbonate }}$ can lead to a dramatic capacity decrease from $250 \mathrm{mAh} / \mathrm{g}$ 
to $125 \mathrm{mAh} / \mathrm{g}$ at the $\mathrm{C} / 10$ rate in the first discharge; however, as shown in Figure 9, $\mathrm{C}_{\text {hydroxide }}$ with a range of 1.54 to $1.67 \mathrm{Li}$ in $\mathrm{Li}_{\mathrm{x}} \mathrm{Ni}_{0.25} \mathrm{Mn}_{0.75} \mathrm{O}_{2+\delta}$ can deliver specific capacities higher than $225 \mathrm{mAh} / \mathrm{g}$ at the $\mathrm{C} / 3$ rate in the first discharge. As shown in Figure 10, stable discharge capacities higher than $200 \mathrm{mAh} / \mathrm{g}$ can be delivered from cathodes with lithium content from 1.54 to $1.71 \mathrm{Li}$ at the $\mathrm{C} / 3$ rate $(1 \mathrm{C}$ equivalent to 200 $\mathrm{mA} / \mathrm{g}$ ) for the first 50 cycles. Even though the $1.71 \mathrm{Li}$ cathode material delivered a lower discharge capacity in the first several cycles, the specific capacity slowly approached 200 $\mathrm{mAh} / \mathrm{g}$ after 50 cycles. The performance advantage of the $\mathrm{C}_{\text {hydroxide }}$ may arise from the nanoplate morphology of the primary particles, which shorten the lithium diffusion path, and thus facilitate the activation of $\mathrm{Li}_{2} \mathrm{MnO}_{3}$-like phase.

\section{Conclusions}

Lithium- and manganese-rich cathode materials with excellent electrochemical performance were synthesized via sodium and ammonia hydroxide as the precipitation agents. It was found that ammonia content has a significant effect on both the primary particle size and morphology of agglomerates. When the ammonia concentration was at the higher side, the growth of lamellar primary particles in the lateral direction was promoted, while the thickness of the lamellar primary particles remained at levels less than $50 \mathrm{~nm}$. When the ammonia concentration was at the low side, local concentration of the ammonium-metal ion complex could be too low to sustain effective growth of the particles. Only appropriate ammonia concentrations can promote the lamellar growth in the stacking direction and the effective packing of the primary particles in the agglomerates, which, in turn, enhances the trimming effect provided by effective particle collisions inside the CSTR reactor. As a result, agglomeration with good spherical shape 
and high tap density was expected. The Li-and Mn- rich composite cathode materials synthesized based on these hydroxide precursors have a better tolerance to lithium variations compared to those based on carbonate precursors. This superiority in electrochemical performance could be linked to the primary particle morphology control through the ammonia coprecipitation process.

\section{Acknowledgements}

This research was funded by the U.S. Department of Energy, Freedom CAR, and Vehicle Technologies Office. The electron microscopy was accomplished at the Electron Microscopy Center for Materials Research at Argonne National Laboratory, a U.S. Department of Energy Office of Science Laboratory operated under Contract No. DEAC02-06CH11357 by UChicago Argonne,LLC. 


\section{Reference}

[1] M. Rossouw, M. Thackeray, Mater. Res. Bull. 1991, 26, 463-473.

[2] Z. Lu, D. D. MacNeil, J. R. Dahn, Electrochem. Solid State Lett. 2001, 4, A191A194.

[3] H. Deng, I. Belharouak, R. E. Cook, H. Wu, Y.-K. Sun, K. Amine, J. Electrochem. Soc. 2010, 157, A447-A452.

[4] H. Deng, I. Belharouak, H. Wu, D. Dambournet, K. Amine, J. Electrochem. Soc. 2010, 157, A776-A781.

[5] H. Deng, I. Belharouak, Y.-K. Sun, K. Amine, J. Mater. Chem. 2009, 19, 45104516.

[6] C. S. Johnson, J.-S. Kim, C. Lefief, N. Li, J. T. Vaughey, M. M. Thackeray, Electrochem. Commun. 2004, 6, 1085-1091.

[7] C. S. Johnson, J.-S. Kim, A. J. Kropf, A. J. Kahaian, J. T. Vaughey, L. M. L. Fransson, K. Edström, M. M. Thackeray, Chem. Mater. 2003, 15, 2313-2322.

[8] C. S. Johnson, N. Li, C. Lefief, J. T. Vaughey, M. M. Thackeray, Chem. Mater. 2008, 20, 6095-6106.

[9] S.-H. Kang, S.-H. Park, C. S. Johnson, K. Amine, J. Electrochem. Soc. 2007, 154, A268-A274.

[10] S.-H. Park, S.-H. Kang, I. Belharouak, Y. K. Sun, K. Amine, J. Power Sources 2008, 177, 177-183.

[11] S.-H. Park, S.-H. Kang, C. S. Johnson, K. Amine, M. M. Thackeray, Electrochem. Commun. 2007, 9, 262-268.

[12] Y.-K. Sun, S.-T. Myung, B.-C. Park, J. Prakash, I. Belharouak, K. Amine, Nat. Mater. 2009, 8, 320-324.

[13] S.-H. Kang, J. Kim, M. . Stoll, D. Abraham, Y. Sun, K. Amine, J. Power Sources 2002, 112, 41-48.

[14] S.-H. Kang, M. M. Thackeray, Electrochem. Commun. 2009, 11, 748-751.

[15] Z. Lu, Z. Chen, J. R. Dahn, Chem. Mater. 2003, 15, 3214-3220.

[16] Y. S. Meng, G. Ceder, C. P. Grey, W.-S. Yoon, M. Jiang, J. Bréger, Y. Shao-Horn, Chem. Mater. 2005, 17, 2386-2394.

[17] J. Bareno, C. H. Lei, J. G. Wen, S. -H Kang, I. Petrov, D. P. Abraham, ChemInform 2010, DOI: 10.1002/chin.201018219.

[18] G. Wei, X. Lu, F. Ke, L. Huang, J. Li, Z. Wang, Z. Zhou, S. Sun, Adv. Mater. 2010, $22,4364-4367$.

[19] D. Wang, I. Belharouak, S. Gallagher, G. Zhou, K. Amine, J. Mater. Chem. 2012, 22, 12039-12045.

[20] D. Wang, I. Belharouak, G. M. Koenig, G. Zhou, K. Amine, J. Mater. Chem. 2011, 21, 9290-9295.

[21] B. Mavis, M. Akinc, J. Power Sources 2004, 134, 308-317.

[22] D. Yang, R. Wang, M. He, J. Zhang, Z. Liu, J. Phys. Chem. B 2005, 109, 76547658.

[23] Z. P. Xu, H. C. Zeng, Chem. Mater. 1998, 11, 67-74.

[24] C. Delmas, C. Tessier, J. Mater. Chem. 1997, 7, 1439-1443.

[25] F. Zhou, X. Zhao, A. van Bommel, A. W. Rowe, J. R. Dahn, Chem. Mater. 2009, 22, 1015-1021. 
[26] D. Chen, L. Gao, Chem. Phys. Lett. 2005, 405, 159-164.

[27] J. Lv, L. Qiu, B. Qu, J. Cryst. Growth 2004, 267, 676-684.

[28] A. Delahaye-Vidal, B. Beaudoin, N. Sac-Epée, K. Tekaia-Elhsissen, A. Audemer, M. Figlarz, Solid State Ionics 1996, 84, 239-248.

[29] M.-H. Lee, Y.-J. Kang, S.-T. Myung, Y.-K. Sun, Electrochimica Acta 2004, 50, 939-948.

[30] C. Deng, S. Zhang, B. L. Fu, S. Y. Yang, L. Ma, J. Alloys Compd. 2010, 496, 521527.

[31] C. Coudun, J.-F. Hochepied, J. Phys. Chem. B 2005, 109, 6069-6074.

[32] D. Wang, I. Belharouak, G. Zhou, K. Amine, Adv. Funct. Mater., 2013, 23, 10701075.

[33] J. Cho, Chem. Mater. 2000, 12, 3089-3094.

[34] A. van Bommel, J. R. Dahn, Chem. Mater. 2009, 21, 1500-1503. 


\section{Figure captions}

Figure 1: Average particle size evolution of $\mathrm{Ni}_{0.25} \mathrm{Mn}_{0.75}(\mathrm{OH})_{2}$ precipitates as a function of reaction time for selected reactions with four $\mathrm{M}_{\mathrm{S}} / \mathrm{M}_{\mathrm{A}}$ ratios

Figure 2: Particle size distributions of final collected $\mathrm{Ni}_{0.25} \mathrm{Mn}_{0.75}(\mathrm{OH})_{2}$ precursors for reactions with six $\mathrm{M}_{\mathrm{S}} / \mathrm{M}_{\mathrm{A}}$ ratios

Figure 3: SEM images of $\mathrm{Ni}_{0.25} \mathrm{Mn}_{0.75}(\mathrm{OH})_{2}$ secondary particles synthesized with different $\mathrm{M}_{\mathrm{S}} / \mathrm{M}_{\mathrm{A}}$ ratios in the base solutions: (a) 2:3, (b) 1:1, (c) 3:2, (d) 2:1, (e) 5:2, and (f) $4: 1$

Figure 4: SEM images of $\mathrm{Ni}_{0.25} \mathrm{Mn}_{0.75}(\mathrm{OH})_{2}$ primary particles synthesized with different $\mathrm{M}_{\mathrm{S}} / \mathrm{M}_{\mathrm{A}}$ ratios in the base solutions: (a) 2:3, (b) 1:1, (c) 3:2, (d) 2:1, (e) 5:2, and (f) 4:1 Figure 5: Photos of three filtrated supernatant solutions from precursor-basic solution mixtures with (1) $M_{S} / M_{A}=2: 3$, (2) $M_{S} / M_{A}=1: 1$, and (3) $M_{S} / M_{A}=4: 1$. Two photos on left show $\mathrm{NiSO}_{4}$ and $\left[\mathrm{Ni}\left(\mathrm{NH}_{3}\right)_{n}\right]^{2+}$ solutions as references Figure 2: (a) XRD patterns of $\mathrm{Ni}_{0.25} \mathrm{Mn}_{0.75}(\mathrm{OH})_{2}$ precursors synthesized with different base solutions: $2: 3,1: 1,3: 2,2: 1,5: 2$, and $4: 1$. The $2 \theta$ Bragg positions for $C 2 / \mathrm{m}, I 4_{1} / \mathrm{amd}$, and $P \overline{3} \mathrm{~m}$ phases are drawn together for comparison. (b) Structural configuration of $\beta-\mathrm{Ni}$ $(\mathrm{OH})_{2}$-like phase.

Figure 3: SEM images of cathode primary particles with lithium content from 1.54 to 1.71 Li in $\mathrm{Li}_{\mathrm{X}} \mathrm{Ni}_{0.25} \mathrm{Mn}_{0.75} \mathrm{O}_{2+\delta}$

Figure 8: (a) XRD of cathode materials with lithium content from 1.54 to $1.71 \mathrm{Li}$ in $\mathrm{Li}_{\mathrm{x}} \mathrm{Ni}_{0.25} \mathrm{Mn}_{0.75} \mathrm{O}_{2+\delta}$ and (b) zoom-in view of (003) peaks with peak shift highlighted by the black dash line Figure 4: Voltage profiles in the first cycle with $\mathrm{C} / 10$ rate for lithium cells with lithium content from 1.54 to $1.71 \mathrm{Li}$ in $\mathrm{Li}_{x} \mathrm{Ni}_{0.25} \mathrm{Mn}_{0.75} \mathrm{O}_{2+\delta}$

Figure 10: Cycling performance at $\mathrm{C} / 3$ rate of lithium cells with lithium content from 1.54 to $1.71 \mathrm{Li}$ in $\mathrm{Li}_{\mathrm{x}} \mathrm{Ni}_{0.25} \mathrm{Mn}_{0.75} \mathrm{O}_{2+\delta}$ 


\section{Table captions}

Table 1: Experimental conditions for the $\mathrm{Ni}_{0.25} \mathrm{Mn}_{0.75}(\mathrm{OH})_{2}$ co-precipitation reactions 
Figure 1

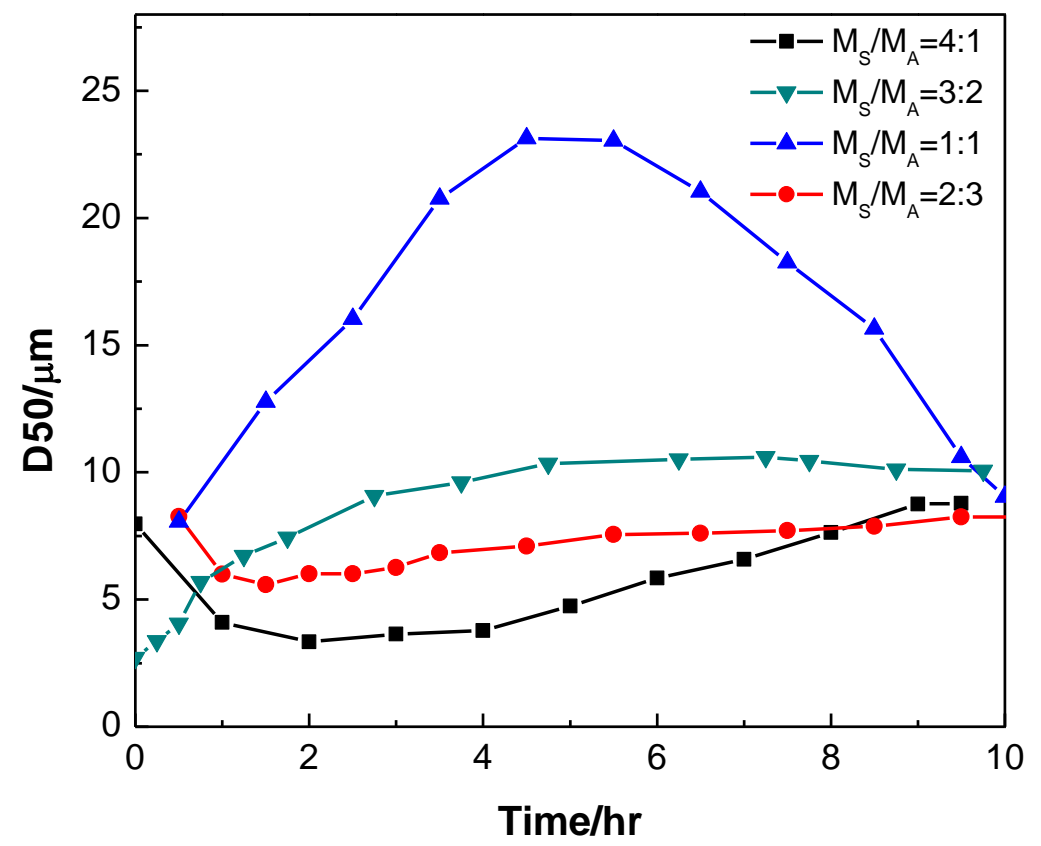


Figure 2

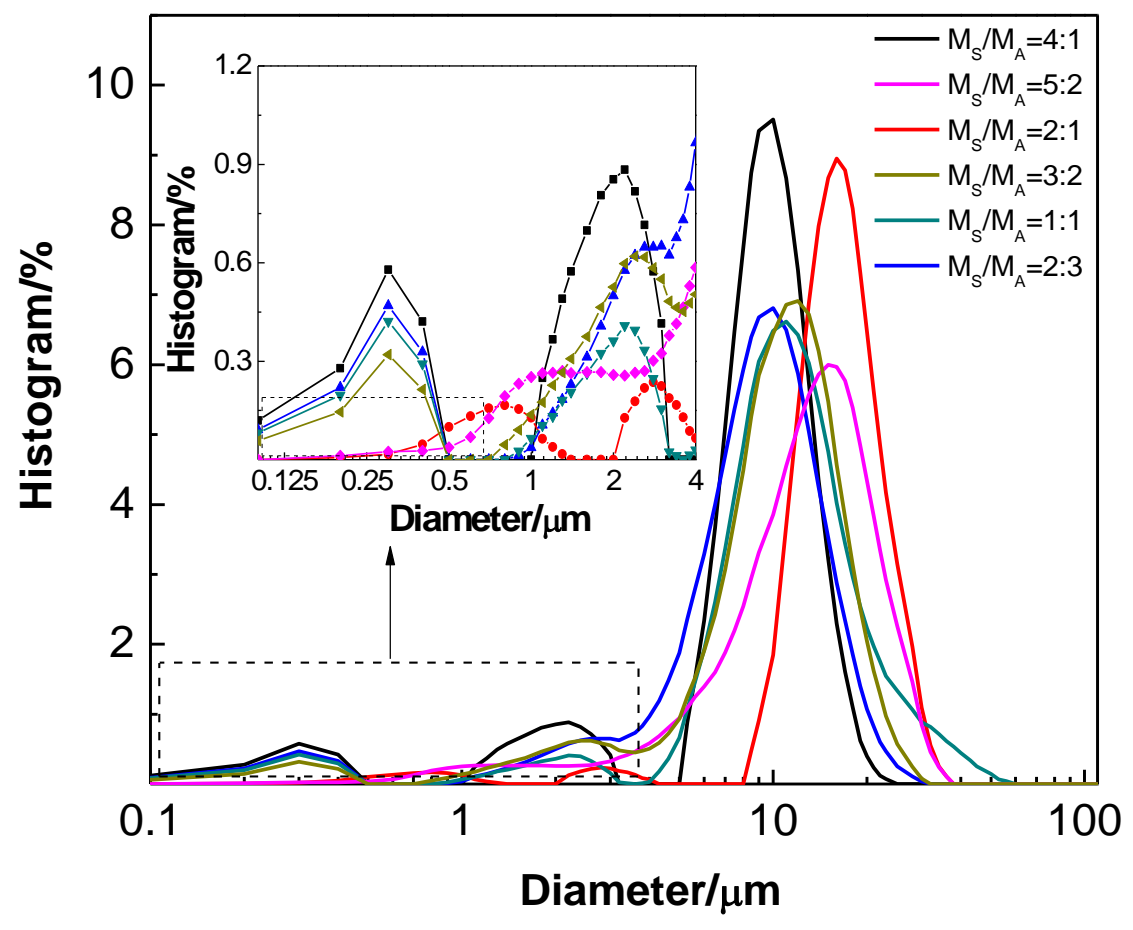


Figure 3
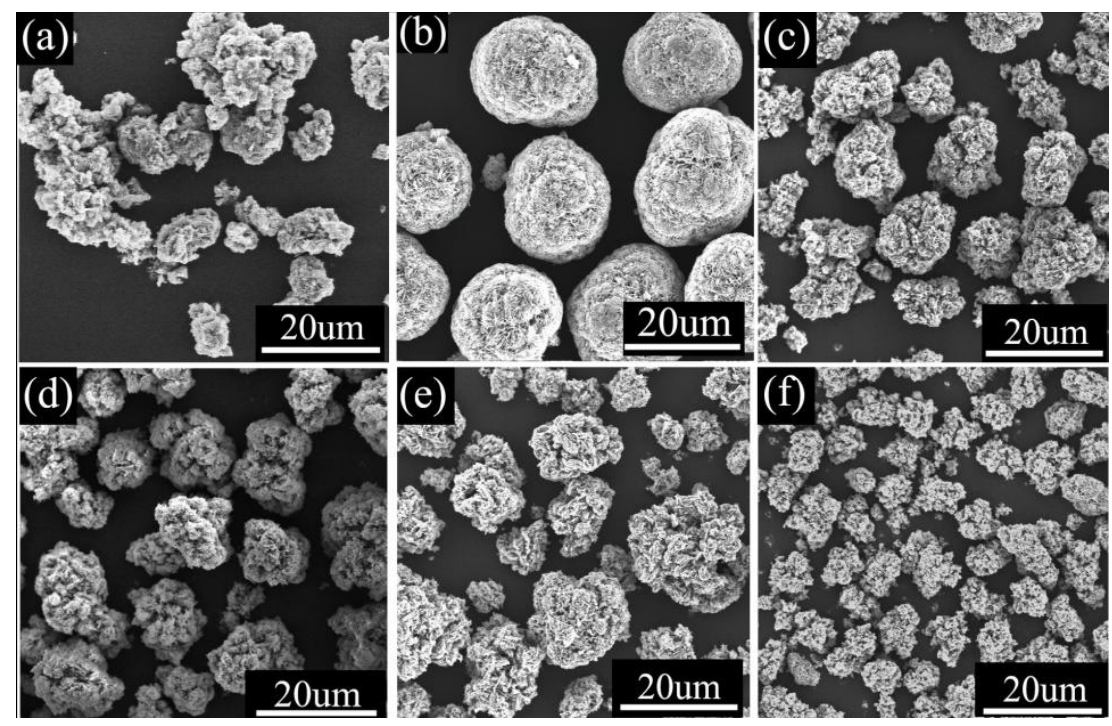
Figure 4
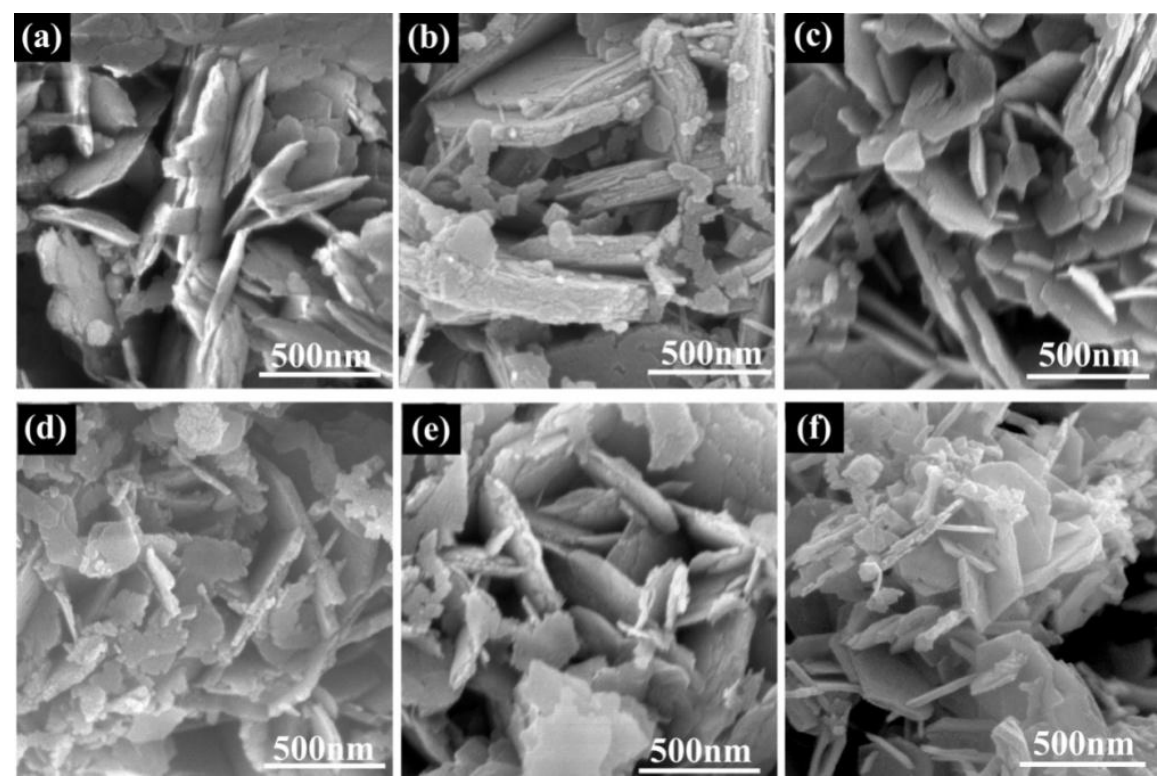
Figure 5

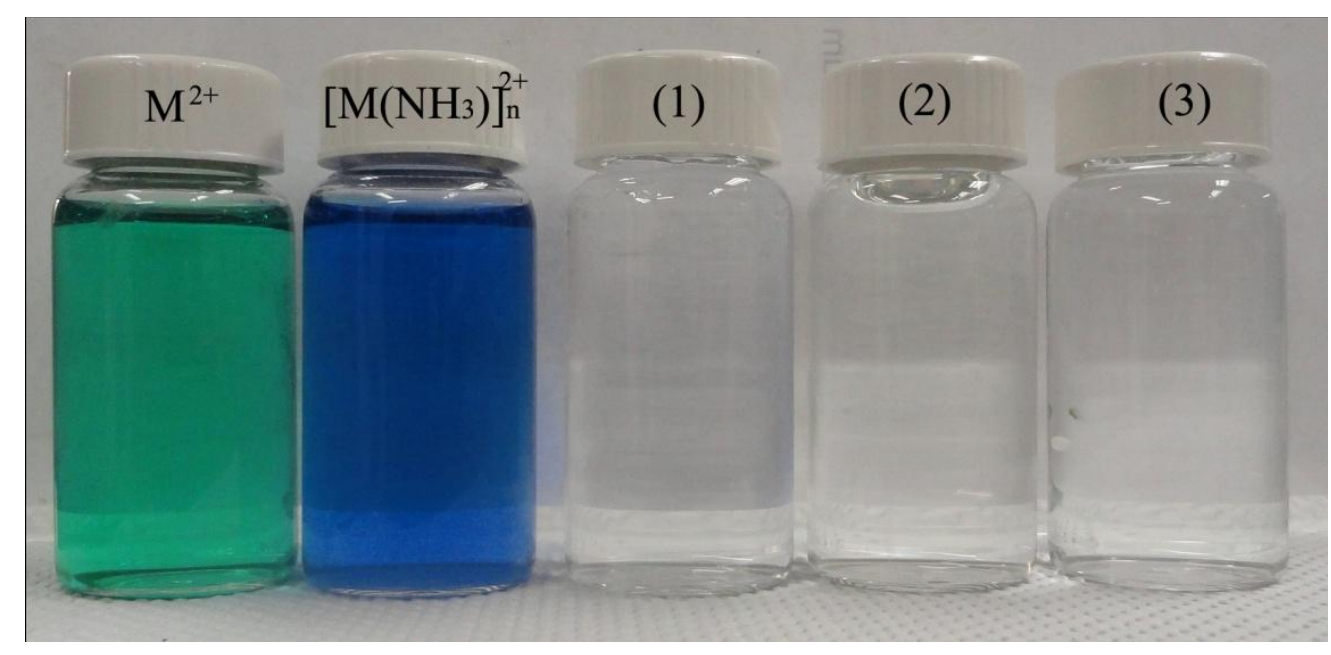


Figure 6
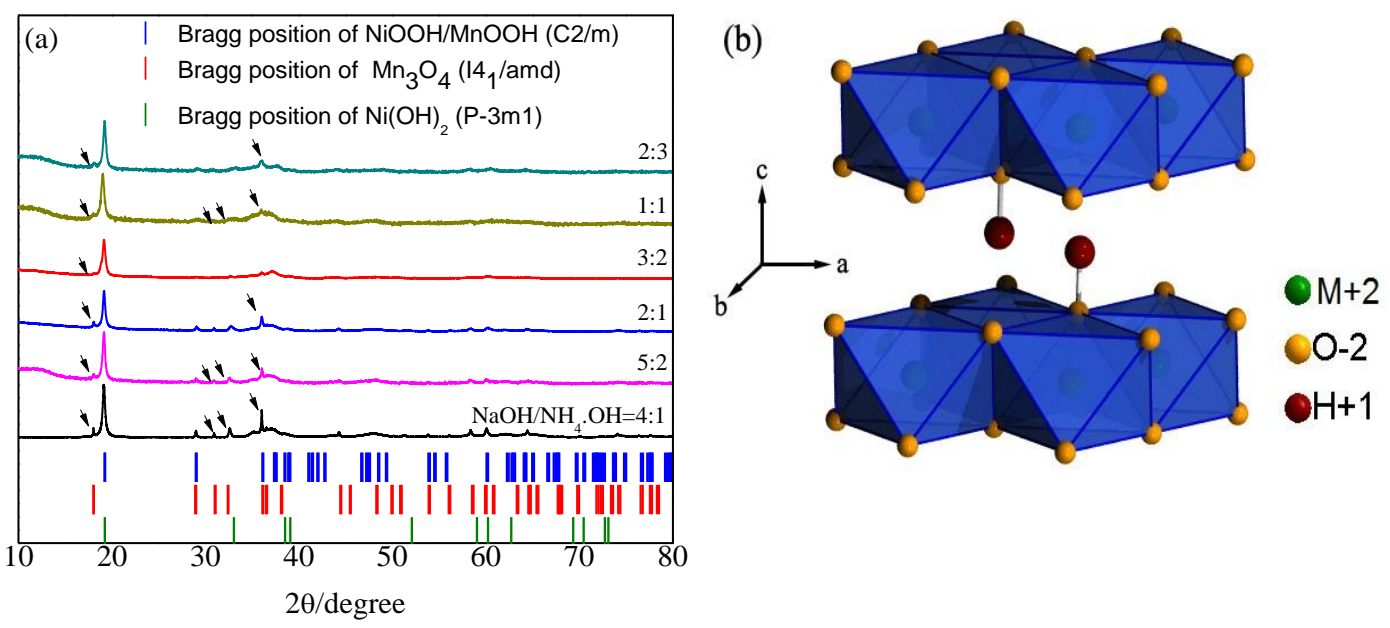
Figure 7
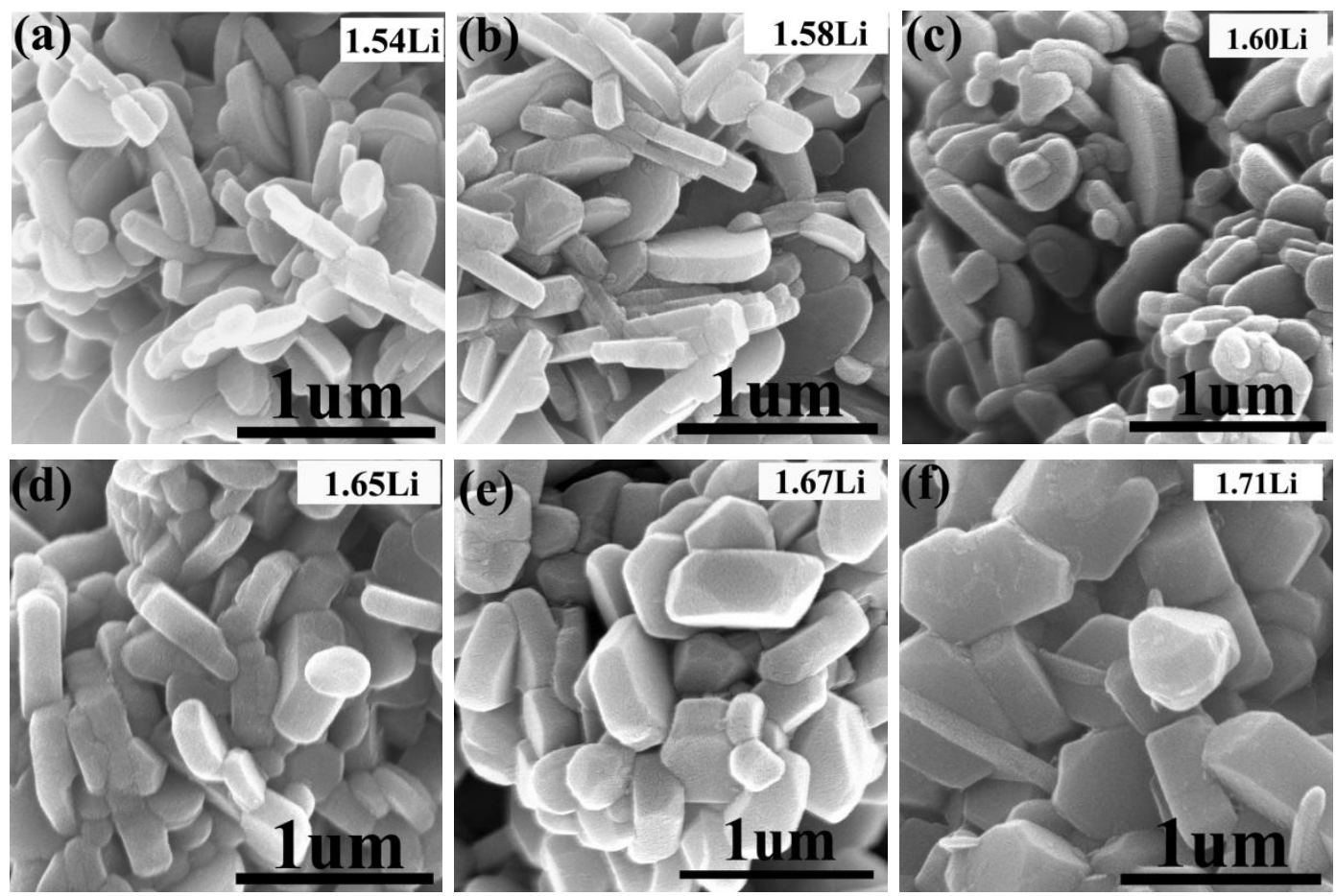
Figure 8

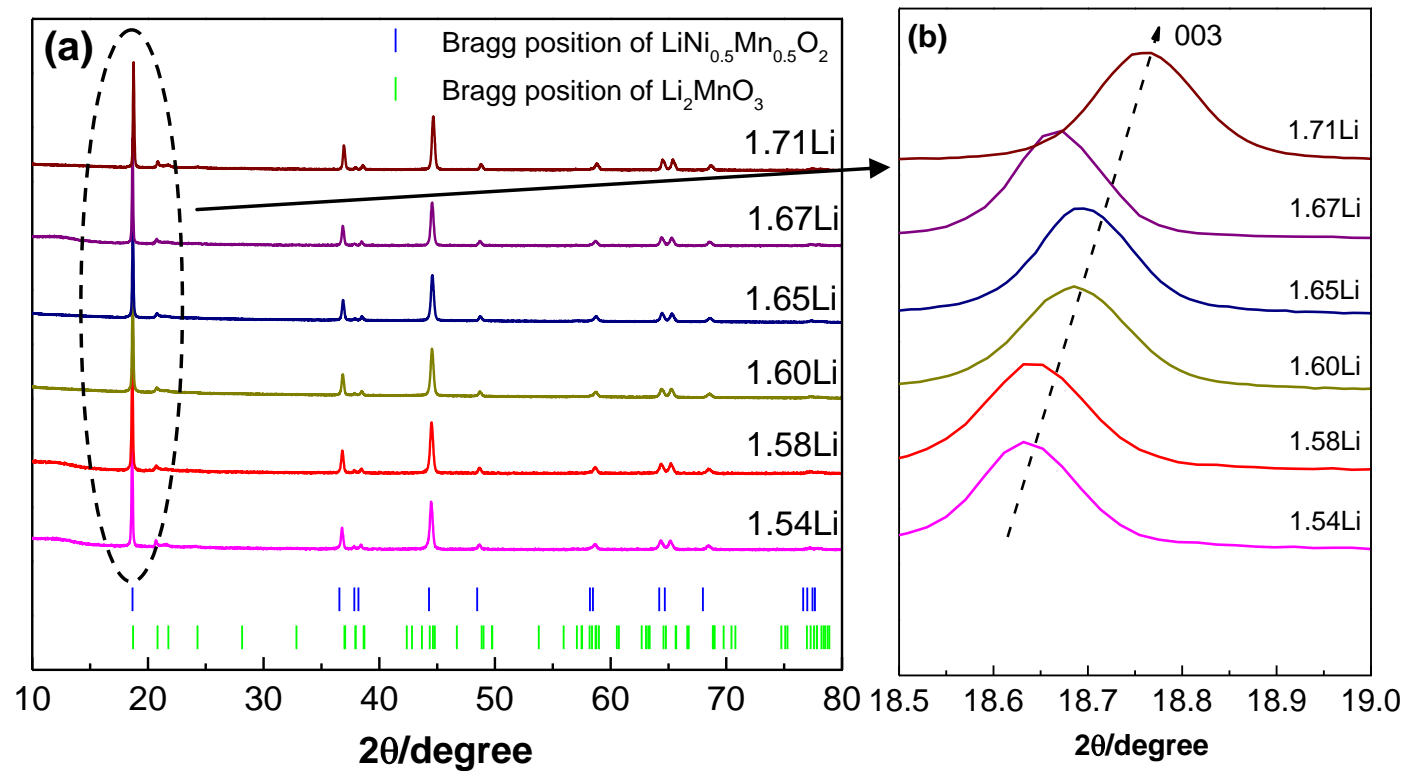


Figure 9

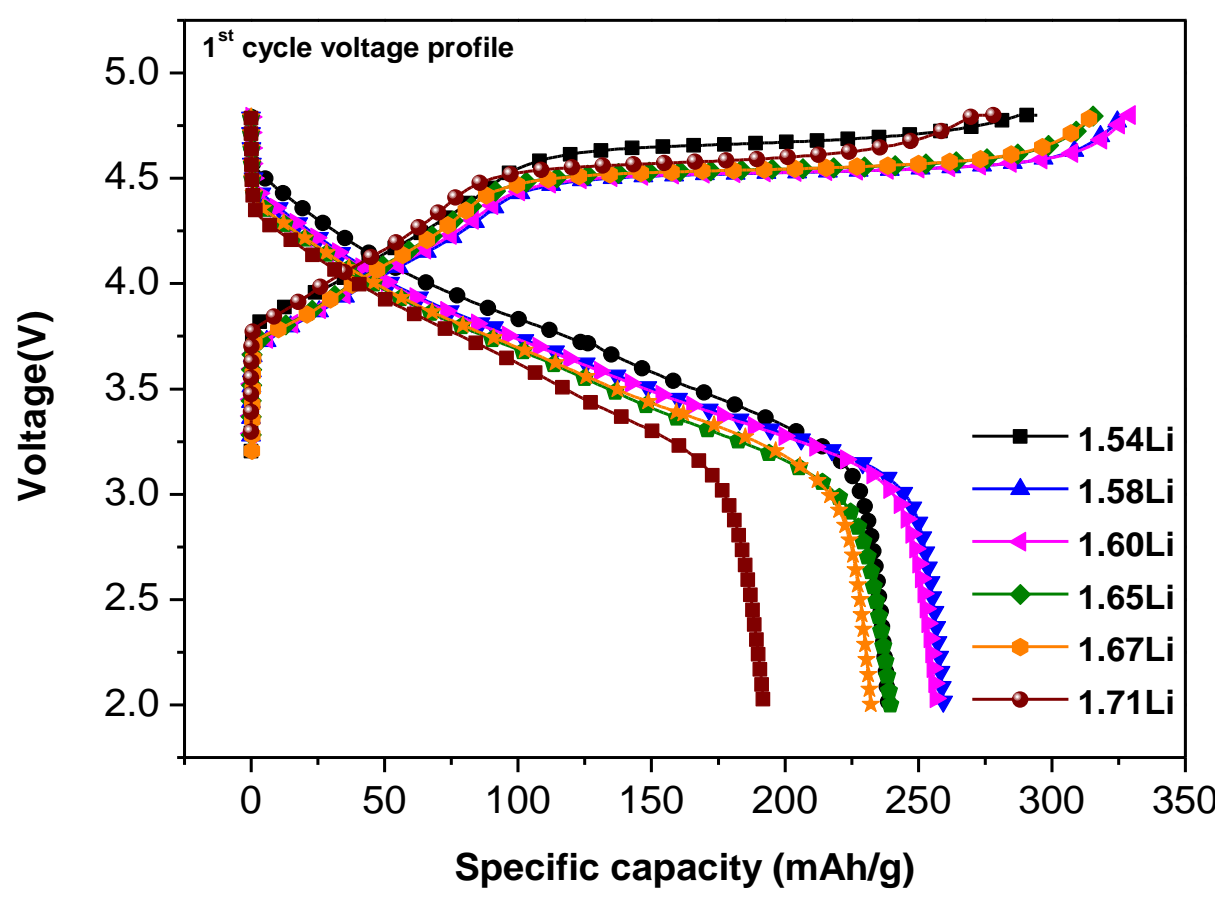


Figure 10

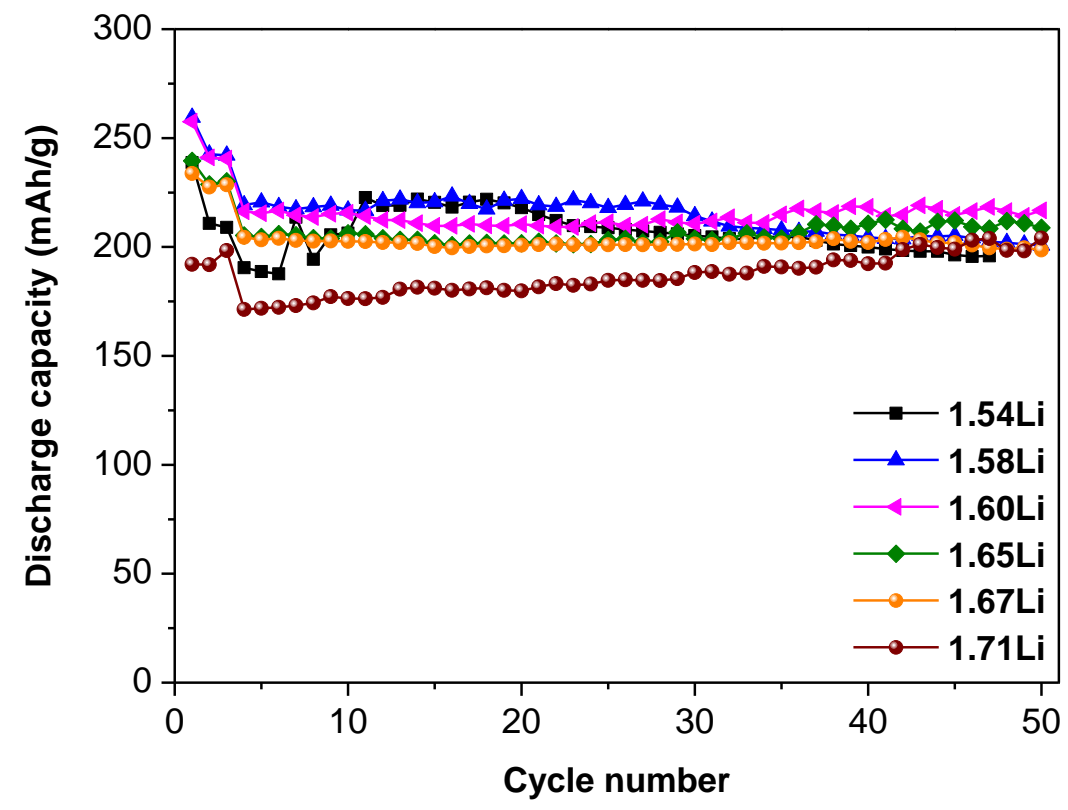


Table 1

\begin{tabular}{ccccccc}
\hline Experiment & $\mathbf{T}\left({ }^{\circ} \mathbf{C}\right)$ & Metal sulfate (M) & Control $\mathbf{P H}$ & $\mathbf{R P M}$ & $\mathbf{N a O H} / \mathbf{N H}_{3} \cdot \mathbf{H}_{2} \mathbf{O}$ & Tap density $\left(\mathbf{g} / \mathbf{c m}^{3}\right)$ \\
\hline$\# 1$ & 60 & 2 & 11 & 1000 & $2: 3$ & 0.74 \\
$\# 2$ & 60 & 2 & 11 & 1000 & $1: 1$ & 1.5 \\
$\# 3$ & 60 & 2 & 11 & 1000 & $3: 2$ & 0.80 \\
$\# 4$ & 60 & 2 & 11 & 1000 & 2 & 0.84 \\
$\# 5$ & 60 & 2 & 11 & 1000 & $5: 2$ & 0.73 \\
$\# 6$ & 60 & 2 & 11 & 1000 & $4: 1$ & 0.54 \\
\hline
\end{tabular}

